\title{
Behavioural plasticity across social contexts is regulated by the directionality of inter-individual differences
}

\author{
Olivia L. Guayasamin ${ }^{\mathrm{a}}$, Iain D. Couzin ${ }^{\mathrm{a}, \mathrm{b}, \mathrm{c}}$, Noam Y. Miller ${ }^{\mathrm{a}, \mathrm{d}, *}$ \\ a Department of Ecology and Evolutionary Biology, 106A Guyot Hall, Princeton University, Princeton, NJ 08544, USA \\ ${ }^{\mathrm{b}}$ Department of Collective Behaviour, Max Planck Institute for Ornithology, Konstanz, Germany \\ ${ }^{c}$ Chair of Biodiversity and Collective Behaviour, Department of Biology, University of Konstanz, Konstanz, Germany \\ ${ }^{\mathrm{d}}$ Department of Psychology, Wilfrid Laurier University, 75 University Ave. West, Waterloo, Ontario N2L 3C5, Canada
}

Keywords:

Zebrafish

Collective behaviour

Plasticity

Individual differences

\begin{abstract}
A B S T R A C T
An individual's behavioural phenotype is a combination of its unique behavioural propensities and its responsiveness to environmental variation, also known as behavioural plasticity. In social species, we must not only explore how individuals respond to variations in the physical environment but also how they react to changes in their social environment. A growing body of work has demonstrated that the behavioural heterogeneity of a group can alter its responsiveness, decision making, and fitness. Whether an individual is more or less extreme than a partner - what we term its 'relative personality' - may also alter individual behavioural responses. We determined exploratory tendencies of individual zebrafish (Danio rerio) and then constructed pairs with varying differences in 'relative personality' to determine the effect of differences between partners on behavioural plasticity. We find that relative personality, but not the magnitude of the difference between partners, is the most important determinant of behavioural plasticity across social treatments. Despite this overall effect, pairs of fish exhibited no predictable leaderfollower interactions, suggesting that details of the experimental paradigm may be important in shaping social dynamics.
\end{abstract}

\section{Introduction}

It is well established that individuals of many species exhibit consistent individual differences in behaviour and that individuals also vary in the degree to which they can modify their behaviour in response to their physical environment (Biro and Adriaenssens, 2013; Brommer, 2013; Dingemanse and Wolf, 2013; Dingemanse et al., 2010a; McElreath et al., 2007; Nussey et al., 2007; Sih and Bell, 2008; Sih and Del Giudice, 2012; Sih et al., 2012, 2004a; Wolf and Weissing, 2010), often referred to as 'personality' and 'plasticity', respectively. Much of the work to date on animal personality has utilized social species as model organisms, yet has been restricted to studying the behaviours of isolated individuals across a range of physical environments. Given that isolated individuals of social species have been shown to behave differently from their behaviour in group settings (Aplin et al., 2014, 2013, 2012; Magnhagen and Bunnefeld, 2009; Magnhagen and

\footnotetext{
* Corresponding author at: Department of Psychology, Wilfrid Laurier University, 75 University Ave. West, Waterloo, Ontario N2L 3C5, Canada.

E-mail address: nmiller@wlu.ca (N.Y. Miller).
}

Staffan, 2005; Magnhagen, 2007; Schuett and Dall, 2009; van Oers et al., 2005; Webster et al., 2007) and that individual differences and social structure may be expected to coevolve in social species (Dingemanse and Wolf, 2013; Dyer et al., 2008; Laskowski and Pruitt, 2014; Tanner and Jackson, 2012), it is important to consider inter-individual differences of members of social species within and across different social contexts.

Current methods of studying behavioural phenotypes typically involve comparing the responses of individuals to a range of physical environments (Briffa et al., 2008; Dosmann and Mateo, 2014; Ord et al., 2010) and/or within a single environmental gradient (Beckmann and Biro, 2013; Dingemanse et al., 2010b; Kluen and Brommer, 2013; Nussey et al., 2007; Quinn et al., 2012; Teyssier et al., 2014), such as different levels of predation risk (Quinn et al., 2012). However, observing how individuals respond to changes in their physical environment is not sufficient for understanding the ecological and evolutionary significance of a particular behaviour in a social species. When the behavioural traits of individuals in groups influence how they perceive, process, and respond to their environment, the specific composition of a group may have fitness consequences for all or some of its members (Cote et al., 2008; Dingemanse and Wolf, 2013; Dyer et al., 2008; 
Laskowski and Pruitt, 2014; Webster and Ward, 2011). For example, social context has the potential to substantially affect an individual's fitness by influencing the interaction between that individual and its physical environment (Magnhagen and Staffan, 2005; Magnhagen, 2007; Schuett and Dall, 2009; Webster et al., 2007), either through influencing an individual's knowledge of the environment by providing access to social information (Aplin et al., 2012; Brown and Laland, 2003; Kruase and Ruxton, 2002; Laland and Williams, 1997; Magnhagen and Staffan, 2003 Laland and Williams, 1997; Magnhagen and Staffan, 2003), or through alteration (by other individuals) of the environment itself (Laskowski and Bell, 2013; Watters and Sih, 2005). The selection pressures that act to maintain inter-individual variation may also depend on collective behavioural phenomena, such that the adaptiveness of any phenotype depends on the ensemble of phenotypes in a particular group (Dingemanse and Wolf, 2013, 2010; Wolf and Krause, 2014; Wolf et al., 2008, 2007).

A growing number of studies have begun to address these effects by comparing an individual's asocial behaviour to their behaviour in a social setting (Aplin et al., 2014, 2013, 2012; Favreau et al., 2014; Herbert-Read et al., 2013; Kurvers et al., 2010, 2009; Magnhagen and Bunnefeld, 2009; Magnhagen and Staffan, 2005; Nakayama et al., 2012; Webster et al., 2007). Individuals of many species tend to conform their behaviour to that of partners or group members (Pike and Laland, 2010) but individual behavioural differences may still be expressed to some degree under social conditions (Aplin et al., 2013; Herbert-Read et al., 2013; King et al., 2015; Kurvers et al., 2011, 2009; Laskowski and Bell, 2014; Magnhagen and Bunnefeld, 2009; Magnhagen and Staffan, 2005; Nomakuchi et al., 2009; Schuett and Dall, 2009; van Oers et al., 2005). For example, "shy" sticklebacks (Gasterosteus aculeatus) will become bolder when placed with a bolder partner, but their asocial behaviour remains a significant predictor of their social behaviour (Jolles et al., 2014). Distinct behavioural phenotypes also appear to demonstrate unique patterns of plasticity. For example, individuals that are boldest, most exploratory, and most aggressive when alone show the smallest change in behaviour upon being placed in a group, and vice versa (Coppens et al., 2010; Harcourt et al., 2009a,b; HerbertRead et al., 2013; Hulthén et al., 2014; King et al., 2015; Koolhaas et al., 1999a,b; Kurvers et al., 2011; Magnhagen and Bunnefeld, 2009; Magnhagen and Staffan, 2005; Øverli et al., 2007; van Oers et al., 2005; Webster and Ward, 2011). Similar conformity effects have been found in studies of social behaviour in human groups (Bikhchandani et al., 1998; Bond and Smith, 1996).

Given that the assessment of inter-individual differences is an inherently relative process - relying on comparisons between behavioural measures within a test population - it is likely that the most informative measure of social effects on individual behaviour will be what we term the 'relative personality': the difference in behaviour between the members of a group. For example, a "shy" individual may respond to a "bold" individual by behaving more boldly (Jolles et al., 2014), but what will the behavioural consequences be if this "shy" individual is paired with an even shyer member of the population, making the "shy" individual the relatively bolder partner? Furthermore, within groups there are frequently changing individual-level interactions among behaviourally heterogeneous group members (Bell and Stamps, 2004; Couzin et al., 2002; Stamps and Groothuis, 2010; Sumpter, 2006). An individual's 'relative personality' will depend on the composition of its current neighbors, and the same individual may behave differently depending on its immediate social context. Some researchers have begun to address this question by testing the same individual in more than one social environment (Cornwallis and Birkhead, 2008; Favati et al., 2014; Jolles et al., 2014; King et al., 2015; Laskowski and Bell, 2013), finding that social status, group membership, personalities of partners, and individual traits can all influence behavioural plasticity.

Previous studies, however, have used randomly constructed groups, in which the relative personality composition of the group could not be experimentally manipulated. It is likely that the particular mix of behavioural phenotypes in a group will have a large effect on most aspects of the group's behaviour, from its cohesiveness to the fitness benefits each individual gains from being part of it (e.g., Pruitt and Reichert, 2011). In species that form fissionfusion groups - where group composition changes on quite short timescales (Croft et al., 2003) - behavioural plasticity will play a large role in determining the success of each individual as well as of the various groups they participate in. Thus, being able to experimentally manipulate the set of behavioural phenotypes comprising a group would allow us to explore the mechanisms by which behavioural differences between group members drive the dynamics of collective behaviour.

Using a well-known model organism, the zebrafish (Danio rerio), we systematically manipulated the 'relative personalities' (as defined above) of pairs of individuals to determine their influence on the plasticity of exploratory behaviour. Pairs of fish were tested in the same environment that was used to establish individual exploratory tendencies, so that the effects of changing social context could be isolated and quantified.

We recorded zebrafish's exploratory behaviour when tested in isolation and when they were with a partner. All trials measured behaviour using the same assay, an open field with a shelter that has been widely used to measure exploratory and boldness tendencies in fish (Harcourt et al., 2010a,b, 2009a,b; Ioannou et al., 2008; King et al., 2013; Maximino et al., 2010b; Nakayama et al., 2012). Each fish participated in two pair trials and we assigned pairings such that each subject was the more exploratory partner (ME) during one condition and the less exploratory partner (LE) during the other, based on scores from their asocial trials, and systematically varied the magnitude of the difference in exploratory tendency between the partners.

\section{Methods}

\subsection{Subjects}

Subjects were 96 (63F; $33 \mathrm{M}$ ) adult zebrafish (Danio rerio) of the WIK strain, bred in the Burdine lab at Princeton University. To identify individual fish for the duration of the study, each fish was injected dorsally at two separate locations with Visible Implant Elastomer tags (VIE; Northwest Marine Technology Inc., Washington, USA; Webster and Laland, 2009). Subjects in the experiment were randomly assigned to 4 groups of 24 uniquely marked fish each. Each group was housed in a single tank. Fish were allowed to recover from the tagging procedure for at least 4 days before experiments began (Doupe et al., 2003). All procedures were reviewed and approved by the Princeton University, NJ, Institutional Animal Care and Use Committee (IACUC; Protocol Number: 1890).

\subsection{Housing and care}

Fish were housed in an environmentally controlled high-density housing rack (Pentair Aquatic Habitats, FL). Lights were on a 12:12 cycle (light:dark); salinity was held between 900 and 1200 microSiemens and the ambient temperature was maintained between 20 and $24^{\circ} \mathrm{C}$. Fish were acclimated to the housing tanks for 4 weeks before experiments began. Once experiments began, fish were fed flake food (TetraMin Tropical Flakes) ad lib. daily after the completion of experimental trials. 


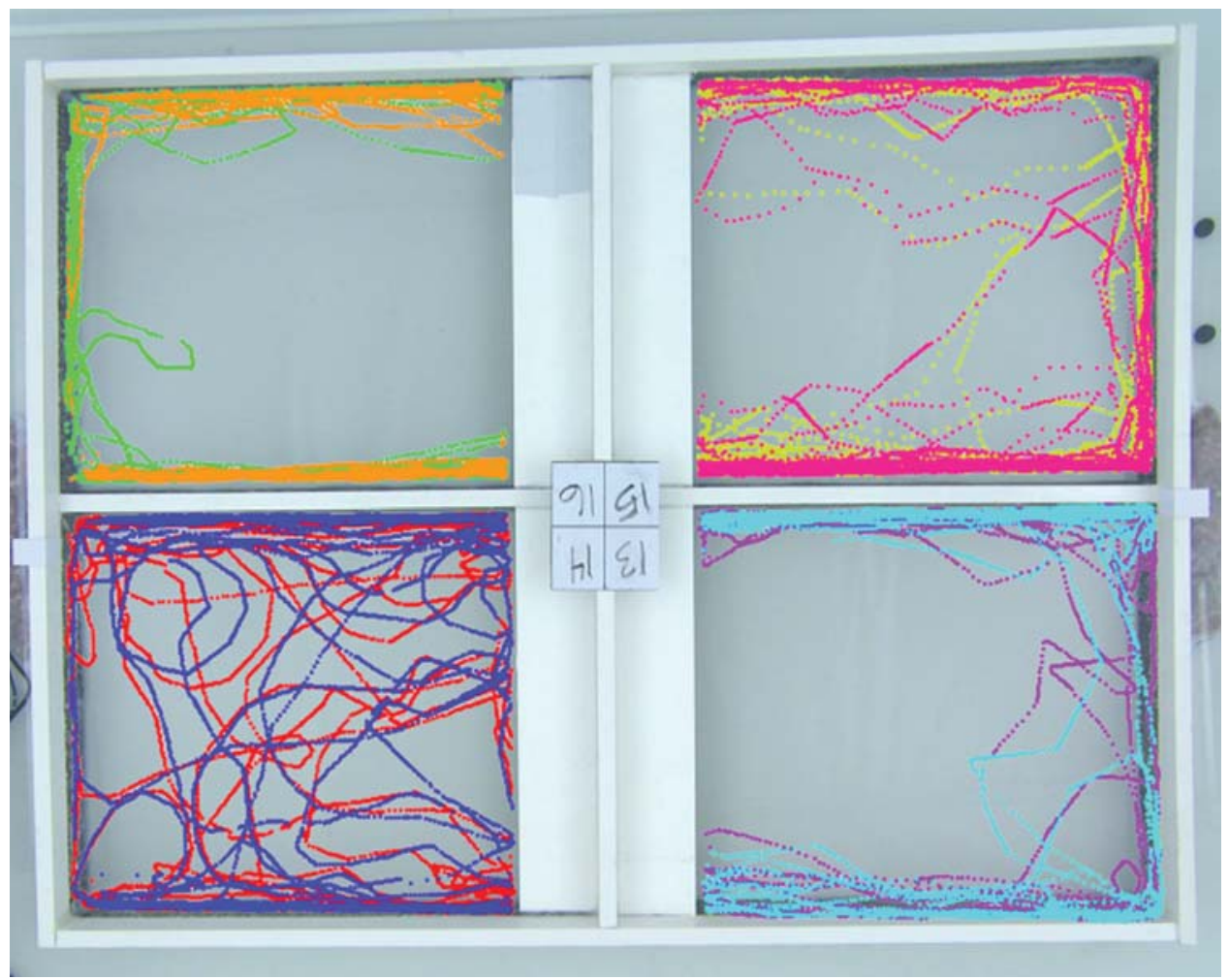

Fig. 1. Testing enclosure and sample trajectories. The photograph is a still image from a data video showing the testing arena used for both asocial and social trials, containing 4 identical enclosures, each with a shelter along one edge (white areas in the image center). Trajectories from a sample set of pair trials are overlaid on the picture. Each color represents the entire trajectory of a single fish over the course of a 10 min trial.

\subsection{Experimental apparatus}

The testing apparatus for both the asocial and pair trials was a $60 \times 45 \mathrm{~cm}$ rectangular white PVC enclosure (Fig. 1). One narrow end of the enclosure held a $7.6 \mathrm{~cm}$ wide plastic overhang just above the water surface with plastic aquarium plants attached to its underside, to serve as a shelter, and all the interior walls of the enclosure were lined with textured transparencies. This design was inspired by prior work with zebrafish demonstrating that open field tasks establish an internal conflict between a preference for dark, protected areas and a drive to explore novel environments (Maximino et al., 2010a, 2010b; Serra et al., 1999; Stephenson et al., 2011). All trials were filmed with an overhead camera (Sony EX1) at $1920 \times 1080$ pixels and at 30 frames per second. Pair trials were additionally photographed every $2 \mathrm{~s}$ (Nikon D7000 DSLR) to aid in the accurate identification of each individual.

Four identical enclosures, as described above, were placed in a $210 \times 120 \times 15 \mathrm{~cm}$ white acrylic tank surrounded by floor-toceiling white curtains (Fig. 1). Water depth was maintained at $7-8 \mathrm{~cm}$ so that the movement of the fish was mostly constrained to 2D. The tank was filled with 'system' water identical to that used in the housing tanks. When fish were not present in the testing tank, bubblers and filters maintained water quality. The arena was lit by four fluorescent tube lights and four Chauvet LED PAR 56-24UVB Blacklights (www.chauvetlighting.com) to enhance the visibility of the elastomer tags.

\subsection{Procedure}

Each fish first completed three asocial trials, in which it was alone in the enclosure. Asocial trials were spaced $48 \mathrm{~h}$ apart. Fish were netted from their home tanks and placed into beakers containing $300 \mathrm{~mL}$ of system water. A single fish was gently placed into each of the four enclosures, allowing four individual trials to be run simultaneously. After 2 min of acclimation time, the movement of each isolated fish was video-recorded for $9 \mathrm{~min}$. All fish were then assigned exploratory scores (see below) on the basis of which pairings were determined. $24 \mathrm{~h}$ after the end of the last asocial trial, each fish participated in two pair trials - in which two fish were placed into each enclosure - spaced $24 \mathrm{~h}$ apart, with a different assigned partner for each trail. Pair trials were otherwise identical to the asocial trials. At the end of the experiment, all fish were sexed (estimated from body dimensions and coloration) and measured (body length: distance from snout to tip of tail fin; body depth: distance from front of dorsal fin to belly).

\subsection{Determining exploratory tendency}

Individual exploratory tendencies were quantified using the trajectory data from all three trials, extracted from the videos using custom software designed in-house (Rosenthal et al., 2015). From these trajectories we extracted the five following behaviours: total distance travelled during the trial, median distance from the closest enclosure wall, median distance from the shelter, total time spent out of the shelter, and median duration of each 'visit' to the shelter. We used median values for distances from the walls and shelter and for shelter visit durations because the distributions of these measures were all highly skewed. All measures were normalized by dividing all recorded values by the maximal possible value of each measure (and so are dimensionless). All raw measures were entered into a Principal Components Analysis (PCA) using Mathematica (v.7, 
Wolfram Research) to give uncorrelated final scores representing the exploratory tendency of each fish.

Only the first component (PC1) resulting from the PCA was found to be significant and it described $57.7 \%$ of the variance (Supplementary materials, Table S.1). The raw measurement loadings on PC1 confirmed our intuition that this component successfully captured exploratory tendency (Table S.2; Dahlbom et al., 2011a; Moretz et al., 2007; Toms and Echevarria, 2014; Toms et al., 2010). For each of the three asocial trials completed by each fish, we multiplied all five raw measurements by the eigenvector of this first principal component, resulting in three exploration tendency scores for each fish (one for each asocial trial). These three scores were then averaged to arrive at a single asocial exploratory tendency score for each fish, denoted $A_{i}$ for individual $i$. This procedure for assigning exploratory scores was established and validated with a separate population of zebrafish, whose behaviours yielded almost identical PCA results (see Appendix A for details).

To allow for direct comparisons of behaviour across both social treatments, individual exploratory behaviour during the pair trials was measured exactly as in the asocial trials, i.e., for this analysis the movement of each member of the pair was quantified independently, as if it were alone. If individual identities were unclear at any point in the video, we combined visual analysis of the higher-resolution DSLR images with a custom MATLAB ( $\mathrm{v}$. R2012B, Mathworks) script and manually assigned identities to each trajectory fragment. The same five measures as above were extracted from the trajectories of each member of the pair separately and the data were transformed using the PCA dimensions determined for the asocial data, ensuring that individual's scores on pair trials are directly comparable to their asocial scores. The first principal component of the resulting score was assigned as the new, social, exploratory tendency score for that individual on that trial, $S_{i}$. Every individual therefore received two new exploratory scores (in addition to their asocial score), one for each of their two social treatments.

For pair trials, we additionally analyzed the coordinated movement of members of each pair during their excursions out from the shelter. We quantified how often each partner initiated the excursion (left the shelter first) or returned to the shelter first. We also measured the mean durations of excursions and the mean distance between the two fish. Finally, we also counted any solo excursions - when a single partner left and returned to the shelter while the other fish remained under the shelter.

\subsection{Pairing fish}

Each individual completed two social treatments: one in which they were the more exploratory (ME) partner and one when they were the less exploratory (LE) partner, a determination based on their asocial exploratory tendency scores $\left(A_{i}\right)$. In addition, we systematically varied the magnitude of the difference in exploratory tendency between the members of a pair, a measure we call the Intra-Pair Exploratory Difference (IPED). The order of the ME and LE social treatments was randomized between fish. The three least (most) exploratory fish in each tank completed both pairings with more (less) exploratory individuals.

\subsection{Measuring plasticity}

Individual plasticity was defined as the difference between asocial and social exploration scores $\left(S_{i}-A_{i}\right)$, and was calculated for each individual for both its ME and LE social trials. This change in behaviour is a known proxy for behavioural plasticity (Sih et al., 2004b). A negative plasticity value indicates that an individual became less exploratory when in a pair relative to when alone, while a positive value indicates an increase in exploratory behaviour. Most importantly, the trajectories for each member of the pair were analyzed independently, as if that fish were alone. In this way, pair trial behaviour could be directly compared to behaviour during the solo trials.

\subsection{Data analysis}

All statistical analyses were conducted in R (v. 3.0.2. R Development Core Team) using the psych, quant psych, car, lme4, and ppcor packages. Results with $\mathrm{P}<0.01$ are reported as significant due to correcting for multiple statistical tests (Bonferonni correction $\alpha=0.01$ ). We tested for individual behavioural change within and across the LE and ME social treatments using Wilcoxon Signed Rank tests. To determine if this change was significantly different from zero, Mann-Whitney $U$ tests were used. To see if partners behaviourally conformed to each other, we used Wilcoxon Signed Rank tests to compare asocial exploratory score differences $\left(A_{i}-A_{j}\right)$ between partners, to their differences in exploratory score during the two social treatments (IPED $\left.=S_{i}-S_{j}\right)$. We further compared the change in score differences between the asocial and social treatments [we denote this $\triangle I P E D=\left(S_{i}-S_{j}\right)-\left(A_{i}-A_{j}\right)$ ]. We constructed 100 lists of shuffled (randomized) pairings of all fish and calculated $\triangle I P E D$ for these random pairs. Real and shuffled distributions were compared using a 2-sample KS test. We examined individual plasticity for the LE and ME social treatments using separate linear mixed models (LMMs). Because pairings were within home tank and occurred over two days, we fitted home tank number and experiment day as random effects. For both models we entered $A_{i}$ and IPED as continuous fixed effects. The fixed effects for the LE fish model had a variance inflation factor (VIF) of 4.039, and the fixed effects for the ME fish had a VIF of 1.059. Step-wise model selection was used to determine the best fitting models. In all cases we present the best fitting models as determined by the Akaike Information Criterion (AIC) and F-tests, as the significance of all terms are unchanged compared to the full models. Finally, correlation analysis with Kendall's $\tau$ was used to determine whether individuals showed similar plasticity in exploratory tendency across the ME and LE social treatments. Because this analysis explored intra-individual plasticity across social treatments, only individuals that participated in both treatments (ME and $\mathrm{LE} ; \mathrm{N}=72$ ) were included. To determine whether the correlation in plasticity across social treatments could be explained by $A_{i}$, partial and semi-partial correlation analyses were employed (Aron et al., 2012).

\section{Results}

There was no effect of sex $(t(94)=0.60, P=0.53)$, body length $(\mathrm{r}=0.03, \mathrm{t}(94)=0.25, \mathrm{P}=0.80)$, or body depth $(\mathrm{r}=0.08, \mathrm{t}(94)=0.81$, $\mathrm{P}=0.42$ ) on asocial exploratory tendency.

\subsection{Asocial exploration is a poor predictor of social behaviour,} but accounts for correlated plasticity across social treatments

Asocial exploratory tendency $\left(A_{i}\right)$ was a poor predictor of exploratory behaviour during the LE or ME social treatments $\left(S_{i}\right)$. Though asocial exploratory tendency was correlated with exploration scores during the LE treatment $(\tau=0.268, \mathrm{P}=0.008)$, it was not correlated with exploration scores in the ME treatment ( $\tau=0.099, \mathrm{P}=0.34$ ). There was also no correlation between an individual's social exploration across social treatments $(\tau=0.139$, $\mathrm{P}=0.18$ ). In addition, an individual's score during pair trials (in both the LE and ME conditions) was not predicted by their partner's asocial exploration score (all Adj. $\mathrm{R}^{2}<0.10$, all $p>0.10$ ).

Plasticity was defined as the change in an individual's exploratory behaviour between the asocial and social trials (i.e., 


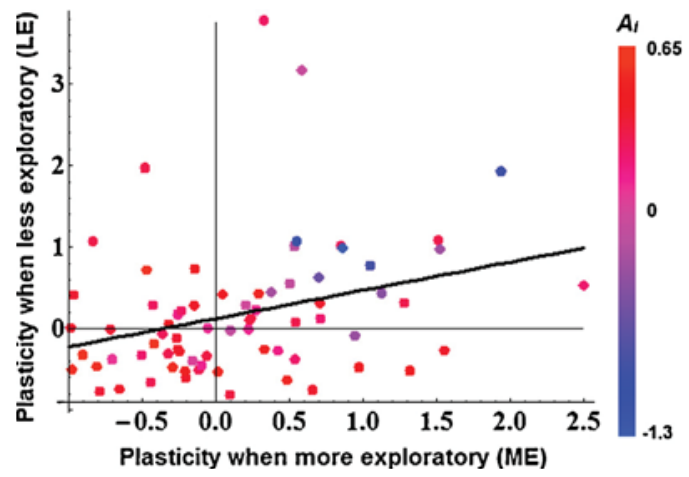

Fig. 2. Individual plasticity correlates across social treatments and depends on asocial exploratory score. The figure shows individuals' plasticity (change in exploratory behaviour from asocial to social treatment) when they were the more exploratory (ME: $\mathrm{x}$-axis) and less exploratory (LE: $\mathrm{y}$-axis) partner. The thick black line is the best-fit linear model of the data $\left(R^{2}=0.09, F=7.3, P=0.009, \beta=0.346[95 \% C I=0.09\right.$, $0.60])$. The color of each dot represents that individual's asocial exploratory score $\left(\mathrm{A}_{\mathrm{i}}\right.$; see color legend at right).

$S_{i}-A_{i}$ ) and calculated separately for trials in which the focal individual was the more (ME) or less (LE) exploratory partner. A bivariate correlation conducted with Kendall's $\tau$ revealed a significant correlation in individual plasticity between the LE and ME social treatments (Fig. 2), such that individuals that demonstrated a large increase in exploratory behaviour during one social treatment tended to also do so in the other $(\tau=0.245, \mathrm{P}=0.007)$. However, there were also significant bivariate correlations between asocial exploratory score and individual plasticity for both the LE $(\tau=-0.302, \mathrm{P}=0.004)$ and $\mathrm{ME}(\tau=-0.268, \mathrm{P}=0.007)$ conditions. Thus, to determine whether asocial exploratory score $\left(A_{i}\right)$ could account for this relationship, we used partial correlation analysis and re-calculated the correlation in plasticity between the LE and ME conditions while controlling for the effects of asocial exploratory score. This caused the observed correlation in plasticity between the LE and ME treatments to lose significance (partial $\tau=0.178, P=0.03$ ), demonstrating that an individual's plasticity across different social treatments is partially explained by their asocial exploratory tendency $\left(A_{i}\right)$, such that less exploratory individuals are more plastic.

\subsection{Individual plasticity is largely determined by relative social condition, and leads to behavioural convergence between partners}

To determine whether partners became more alike in exploratory behaviour during their interaction, we compared the difference in partners' asocial scores to their IPED, the difference between their scores during the social trials (Fig. 3A). The difference between partners' scores decreased from asocial to social trials ( median asocial difference $=0.307$; median IPED $=0.045$; Wilcoxon signed-rank test, $\mathrm{W}=3669, \mathrm{P}<0.001)$. This change in distance between individual scores of partners from the asocial to the social condition, which we denote $\triangle I P E D$, was significantly negative, indicating that partners' exploratory behaviour converged (Fig. 3B; median change $=-0.38$; KS test, compared to randomized data, $\mathrm{D}=0.26, \mathrm{P}<0.00001)$. The convergence in partners' behaviour was largely driven by increased exploration by the less exploratory (LE) individual. In nearly half of all social trials (45 of 96), the individual that was identified as less exploratory (LE) - based on asocial scores $\left(A_{i}\right)$ - exhibited more exploratory behaviour during the social trials than the more exploratory (ME) individual (Fig. 3A, the part of the social distribution that is $<0$ ). Furthermore, during the LE social treatment, individuals displayed increased exploratory behaviour (compared to their exploratory behaviour in isolation), but this effect was not seen during the ME social treatment (Fig. 3C). When individuals we relatively less exploratory than their partner (LE social treatment), the increase in exploratory behaviour was significantly greater than zero $(U=3497, P<0.001$; median change in score $=0.299$ ). However, when individuals were the more exploratory partner (ME social treatment), they did not exhibit significant plasticity $(U=2315, P=0.96$; median change in score $=-0.075$ ). Comparing plasticity across social treatments confirmed that individuals expressed significantly different patterns of plasticity depending on whether they were the relatively less exploratory or more exploratory member of a pair (Fig. 3C; KS test, $\mathrm{D}=0.25, \mathrm{P}=0.005$ ).

\subsection{Asocial exploratory tendencies do not predict the coordination of movement between individuals during pair trials}

The more exploratory (ME) individual was not more likely to initiate excursions from the shelter $(t(190)=0.176, P=0.392)$, be the first to return to the shelter $(t(190)=0.011, P=0.398)$, or perform more solo excursions out from the shelter $(\mathrm{t}(190)=0.009, \mathrm{P}=0.398$ ). Higher asocial scores $\left(A_{i}\right)$ were also not significantly correlated with initiating excursions $(\mathrm{r}=0.137, \mathrm{t}(94)=1.336, \mathrm{P}=0.092)$, being the first to return to the shelter $(r=0.021, t(94)=0.203, P=0.420)$, or performing more solo excursions $(\mathrm{r}=0.124, \mathrm{t}(94)=1.216, \mathrm{P}=0.114)$. The difference in asocial scores between partners (IPED) did not correlate with mean excursion duration $(r=0.180, t(94)=1.771$, $\mathrm{P}=0.080)$ or the mean distance between the fish $\left(\mathrm{r}<-8.6 \times 10^{-18}\right.$, $\left.\mathrm{t}(94)<-8.4 \times 10^{-17}, \mathrm{P}=1\right)$. In summary, we did not find evidence that differences in asocial exploratory tendency directly determine the coordination of movement between partners.

\subsection{Asocial exploratory tendency predicts the magnitude and direction of behavioural change}

While relative exploratory tendency - whether an individual was more or less exploratory - determined whether individuals exhibited significant plasticity during the social trials, we attempted to understand what factors predicted individual plasticity in exploratory behaviour within each social treatment.

For both social treatments, the best fitting linear model of exploratory score had only one significant predictor variable: asocial exploratory score $\left(A_{i}\right.$; Table 1 , bottom). Individuals with the lowest asocial exploratory scores demonstrated the greatest plasticity: a large increase in exploratory score from asocial to social trials. However, the best fitting model did not include the magnitude of inter-individual differences in exploratory tendency between partners as a predictor variable. In other words, in our data, the primary determinant of plasticity was individual exploratory scores. The magnitude of the differences in exploratory tendency between partners did not significantly predict plasticity.

\section{Discussion}

We examined the exploratory behaviour of zebrafish both alone and in pairs specifically constructed to explore the effects of differences in exploratory tendencies. By measuring exploratory behaviour in the exact same environment during both the asocial and social trials, (i.e., by analyzing individual movement during pair trials as if the focal fish were alone), we were able to isolate and quantify the effects of changing social treatment on individual behaviour. We found that the degree of plasticity in exploratory behaviour an individual displays is primarily determined by their relative exploratory tendency. Individuals only displayed significant plasticity - defined as the change in their behaviour from the asocial to the social treatments - when they were the less 

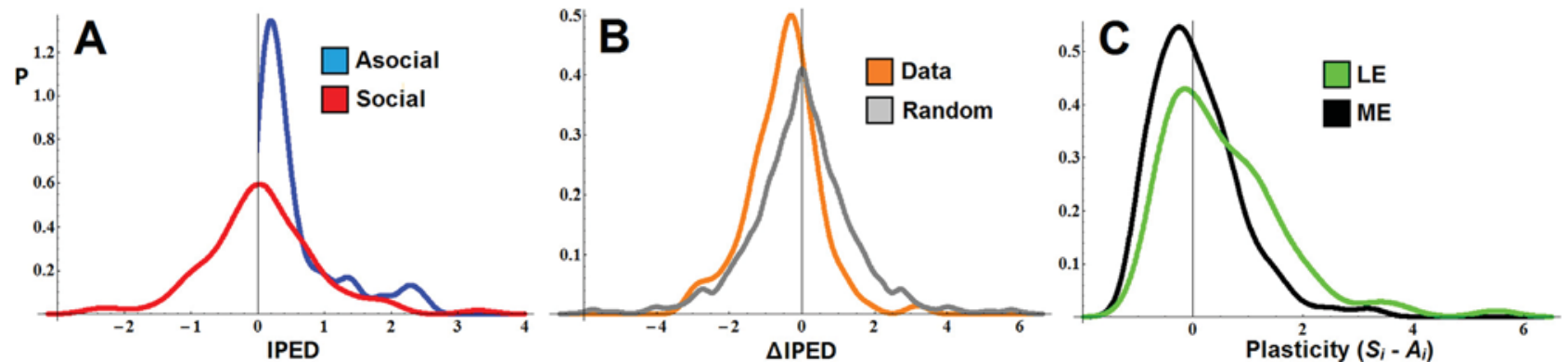

Fig. 3. Distributions of differences in partner exploratory behaviour and plasticity. A. Density distributions of differences (between paired individuals) in asocial (blue) and social (red) exploratory scores (IPED). Only positive asocial values are shown (i.e., for each pair, the score for the less exploratory (LE) individual is subtracted from that of the more exploratory (ME) individual), and the same comparisons are used for the social distribution. B. The change in differences between partners from the asocial to the social trials $(\triangle I P E D)$. The figure shows density distributions of $\triangle$ IPED for real (orange) and randomized (grey) pairings; see text for details. C. Density distributions of plasticity (change in exploratory tendency between the asocial and social treatments; $S_{i}-A_{i}$ ) when individuals were the more exploratory (ME; black) and less exploratory (LE; green) partner. See text for statistical comparisons. All distributions were created using the SmoothHistogram function in Mathematica (v.9, Wolfram Research).

Table 1

Multiple regression analysis of individual plasticity for both social treatments. Different models were run for each treatment (ME and LE). In both treatments, individuals with lower asocial exploration scores $\left(A_{i}\right)$ demonstrated greater plasticity in the direction of increasing exploratory behaviour.

\begin{tabular}{|c|c|c|c|c|c|}
\hline & B & SE B & $\beta$ & $\mathrm{t}$ & $\mathrm{P}$ \\
\hline \multicolumn{6}{|c|}{ More exploratory treatment (Adj. $R^{2}=0.23$, vs. null model $F(2,93)=15.26, P<0.001$ ) } \\
\hline Constant & 0.145 & 0.111 & & 1.305 & 0.195 \\
\hline$A_{i}$ & -0.740 & 0.165 & -0.416 & -4.497 & $<0.001$ \\
\hline \multicolumn{6}{|c|}{ Less exploratory treatment (Adj. $R^{2}=0.50$, vs. null model $F(1,94)=97.82, P<0.001$ ) } \\
\hline Constant & 0.308 & 0.083 & & 3.72 & $<0.001$ \\
\hline$A_{i}$ & -0.911 & 0.092 & -0.714 & -9.89 & $<0.001$ \\
\hline
\end{tabular}

Note: $N=96$

exploratory partner (LE treatment). This plasticity was in the direction of increasing exploratory behaviour, such that in almost half of our pairings, the less exploratory (LE) individuals actually displayed stronger exploratory tendencies during the pair trials than their more exploratory (ME) condition partners. Within each social treatment, the best predictor of plasticity was an individual's asocial exploratory tendency $\left(A_{i}\right)$, with less exploratory individuals exhibiting greater plasticity, in line with predictions from the literature (Coppens et al., 2010; Harcourt et al., 2009a,b; Herbert-Read et al., 2013; Hulthén et al., 2014; Jolles et al., 2015, 2014; King et al., 2015; Koolhaas et al., 1999a,b; Kurvers et al., 2011; Magnhagen and Bunnefeld, 2009; Magnhagen and Staffan, 2005; Øverli et al., 2007; Ruiz-Gomez et al., 2008; Sneddon, 2003; van Oers et al., 2005; Ward et al., 2004; Webster and Ward, 2011).

The increase in exploratory behaviour by the less exploratory individuals resulted in a convergence of exploratory behaviours between partners during the pair trials, an effect that is in line with the 'conformity hypothesis' (King et al., 2015; Magnhagen, 2007; Webster and Ward, 2011). Results from previous work suggest a mechanism for this conformity effect: less exploratory individuals are known to be more responsive to their social environment and to pay more attention to social cues (Coppens et al., 2010; Harcourt et al., 2009a,b; Jolles et al., 2015, 2014; Koolhaas, 2008; Koolhaas et al., 1999a; Kurvers et al., 2010; Magnhagen and Bunnefeld, 2009; Magnhagen and Staffan, 2005; Ruiz-Gomez et al., 2008; Sneddon, 2003; van Oers et al., 2005; Ward et al., 2004). By contrast, more exploratory individuals do not attend or react as strongly to their social situation. Conformity effects are therefore the result of less exploratory individuals adapting their behaviour to match that of their more exploratory partners.

Although the least exploratory individuals were the most plastic across social treatments, our analysis contradicts this hypothesized mechanism for conformity. We find that the amount of increased exploration displayed by the less exploratory partner - their 'adjustment' to the behaviour of their more exploratory partner does not depend on the magnitude of the difference in exploratory tendency between the partners. In our data, the appearance of a conformity effect was driven by the least exploratory individuals showing the largest response to being in a social situation, but the magnitude of this response was not determined by the exploratory tendency of their partner. If conformity were being driven by the less exploratory individual in a pair attempting to match the behaviour of the more exploratory partner, we would have expected to see greater adjustments where the disparity between the partners was greater.

Unlike many published findings (Harcourt et al., 2010a,b, 2009a,b; Jolles et al., 2015, 2014; Leblond and Reebs, 2006; Nakayama et al., 2012), differences in asocial exploratory tendency were not found to directly determine the coordination of movement or leadership behaviours between partners in our experiment. Several studies of personality in a social context have shown that bolder individuals (which may share traits with our more exploratory individuals) become 'leaders' when paired with a shyer partner: they are more likely to leave a shelter first and to lead the pair's excursion out from the shelter (Harcourt et al., 2010a,b, 2009a,b; Jolles et al., 2015, 2014; Leblond and Reebs, 2006; Nakayama et al., 2012). We observed no such effects, and speculate that there are several potential reasons why. First, this study used zebrafish as a model organism, and it is possible that zebrafish coordinated movement is different from that of species used in prior work (primarily Gasterosteus aculeatus). Second, we used a purely exploratory task during the asocial and social trials. Unlike in other published studies, our exploratory task was not combined with a foraging task (i.e., there was no food in the enclosure and the fish were not food-deprived).

Perhaps most importantly, the setup of our pair trials differs in a key respect from that of most prior work. Pairs in our study were able to interact freely throughout their pair sessions, whereas in most previous work a barrier was kept between the fish to allow for individual identification (Harcourt et al., 2010a,b, 2009a,b; Jolles et al., 2016, 2015, 2014; Nakayama et al., 2012). The presence of a barrier during social interactions may confound social interac- 
tions with wall following behaviour, which both the current work and others (Dahlbom et al., 2011b; Ferrari et al., 2014; Jolles et al., 2015, 2014; Maximino et al., 2010b) have shown to be greater in less exploratory individuals. The fact that we did not observe any effects of exploratory tendency on leadership in our free-swimming pairs suggests that the presence of a barrier during social trials may fundamentally alter the dynamics of social interactions. Despite the lack of clear leader-follower dynamics, our data do indicate that individual behaviour was affected by the presence of a partner.

\section{Conclusions}

Consistent inter-individual differences, often termed 'personality', limit an individual's flexibility in reacting to changing environmental conditions - both physical and social. But the degree of plasticity across conditions that an individual displays can itself be considered a personality trait. Our results demonstrate that plasticity across social contexts in zebrafish varies between individuals in a consistent manner, is correlated to their asocial exploratory tendencies, and depends on the sign - but not the magnitude - of the relative personality of their partner. Plasticity is likely to also depend on many other factors that remain to be explored such as group size, the personality composition of the group, and the types of environmental challenges the group faces.

\section{Funding sources}

This work was supported by the National Science Foundation (GRFP to O.L.G.), National Science Foundation (PHY-0848755, IOS-1355061, EAGER-IOS-1251585 to I.D.C), ONR (N00014-091-1074, N00014-14-1-0635 to I.D.C), ARO (W911NG-11-1-0385, W911NF-14-1-0431 to I.D.C), Human Frontier Science Program (RGP0065/2012 to I.D.C), and an NSERC Post-Doctoral Fellowship to N.Y.M.

\section{Acknowledgements}

We thank A. Strandburg-Peshkin, C. Twomey, and S. Fogarty for insightful discussions, C. Twomey for writing our custom tracking software, the lab of R. Burdine for providing the subjects used in these experiments, and C. Hasty for assistance with animal care.

\section{References}

Aplin, L.M., Farine, D.R., Morand-Ferron, J., Sheldon, B.C., 2012. Social networks predict patch discovery in a wild population of songbirds. Proc. Biol. Sci. 279 4199-4205, http://dx.doi.org/10.1098/rspb.2012.1591.

Aplin, L.M., Farine, D.R., Morand-Ferron, J., Cole, E.F., Cockburn, A., Sheldon, B.C., 2013. Individual personalities predict social behaviour in wild networks of great tits (Parus major). Ecol. Lett. 16, 1365-1372, http://dx.doi.org/10.1111/ ele.12181.

Aplin, L.M., Farine, D.R., Mann, R.P., Sheldon, B.C., 2014. Individual-level personality influences social foraging and collective behaviour in wild birds. Proc. Biol. Sci. 281, 20141016, http://dx.doi.org/10.1098/rspb.2014.1016.

Aron, A., Coups, E.J., Aron, E.N., 2012. Statistics for Psychology, 6th edition. Pearson.

Beckmann, C., Biro, P.A., 2013. On the validity of a single (Boldness) assay in personality research. Ethology 119, http://dx.doi.org/10.1111/eth.12137, n/a-n/a.

Bell, A.M., Stamps, J.a., 2004. Development of behavioural differences between individuals and populations of sticklebacks, Gasterosteus aculeatus. Anim. Behav. 68, 1339-1348, http://dx.doi.org/10.1016/j.anbehav.2004.05.007.

Bikhchandani, S., Hirshleifer, D., Welch, I., 1998. Learning from the behavior of others: conformity, fads, and informational cascades. J. Econ. Perspect. 12, 151-170.
Biro, P.A., Adriaenssens, B., 2013. Predictability as a personality trait: consistent differences in intraindividual behavioral variation. Am. Nat. 182, 621-629, http://dx.doi.org/10.1086/673213.

Bond, R., Smith, P.B., 1996. Culture and conformity: a meta-analysis of studies using Asch's (1952b 1956) line judgement task. Psychol. Bull.

Briffa, M., Rundle, S.D., Fryer, A., 2008. Comparing the strength of behavioural plasticity and consistency across situations: animal personalities in the hermit crab Pagurus bernhardus. Proc. Biol. Sci. 275, 1305-1311, http://dx.doi.org/10. 1098/rspb.2008.0025.

Brommer, J.E., 2013. Variation in plasticity of personality traits implies that the ranking of personality measures changes between environmental contexts: calculating the cross-environmental correlation. Behav. Ecol. Sociobiol. 67, 1709-1718, http://dx.doi.org/10.1007/s00265-013-1603-9.

Brown, C., Laland, K.N., 2003. Social learning in fishes: a review. Fish Fish. 4, 280-288, http://dx.doi.org/10.1046/j.1467-2979.2003.00122.x.

Coppens, C.M., de Boer, S.F., Koolhaas, J.M., 2010. Coping styles and behavioural flexibility: towards underlying mechanisms. Philos. Trans. R. Soc. Lond. B: Biol. Sci. 365, 4021-4028, http://dx.doi.org/10.1098/rstb.2010.0217.

Cornwallis, C.K., Birkhead, T.R., 2008. Plasticity in reproductive phenotypes reveals status-specific correlations between behavioral, morphological, and physiological sexual traits. Evolution 62, 1149-1161, http://dx.doi.org/10. $1111 / \mathrm{j} .1558-5646.2008 .00346 . x$.

Cote, J., Dreiss, a, Clobert, J., 2008. Social personality trait and fitness. Proc. Biol. Sci. 275, 2851-2858, http://dx.doi.org/10.1098/rspb.2008.0783.

Couzin, I.D., Krause, J., James, R., Ruxton, G.D., Franks, N.R., 2002. Collective memory and spatial sorting in animal groups. J. Theor. Biol. 118, 1-11, http:// dx.doi.org/10.1006/yjtbi.3065.

Croft, D.P., Arrowsmith, B.J., Bie by, J., Skinner, K., White, E., Couzin, I.D., Magurran, A.E., Ramnarine, I., Krause, J., 2003. Mechanisms underlying shoal composition in the Trinidadian guppy, Poecilia reticulata. Oikos 100, 429-438.

Dahlbom, S.J., Lagman, D., Lundstedt-Enkel, K., Sundström, L.F., Winberg, S., 2011a. Boldness predicts social status in zebrafish (Danio rerio). PLoS One 6, e23565, http://dx.doi.org/10.1371/journal.pone.0023565.

Dahlbom, S.J., Lagman, D., Lundstedt-Enkel, K., Sundström, L.F., Winberg, S., 2011b. Boldness predicts social status in zebrafish (Danio rerio). PLoS One 6, e23565, http://dx.doi.org/10.1371/journal.pone.0023565.

Dingemanse, N.J., Wolf, M., 2010. Recent models for adaptive personality differences: a review. Philos. Trans. R. Soc. Lond. B: Biol. Sci. 365, 3947-3958, http://dx.doi.org/10.1098/rstb.2010.0221.

Dingemanse, N.J., Wolf, M., 2013. Between-individual differences in behavioural plasticity within populations: causes and consequences. Anim. Behav. 85, 1031-1039, http://dx.doi.org/10.1016/j.anbehav.2012.12.032.

Dingemanse, N.J., Kazem, A.J.N., Réale, D., Wright, J., 2010a. Behavioural reaction norms: animal personality meets individual plasticity. Trends Ecol. Evol. 25, 81-89, http://dx.doi.org/10.1016/j.tree.2009.07.013.

Dingemanse, N.J., Kazem, A.J.N., Réale, D., Wright, J., 2010b. Behavioural reaction norms: animal personality meets individual plasticity. Trends Ecol. Evol. 25 , 81-89, http://dx.doi.org/10.1016/j.tree.2009.07.013.

Dosmann, A., Mateo, J.M., 2014. Food, sex and predators: animal personality persists with multidimensional plasticity across complex environments. Anim. Behav. 90, 109-116, http://dx.doi.org/10.1016/j.anbehav.2014.01.011.

Doupe, R.G., Partridge, G.J. Lymbery, A.J., 2003. Visible implant fluorescent elastomer tags as pedigree markers for applied aquaculture: an evaluation using black bream Acanthopagrus butcheri. Aquacul. Res. 34, 681-683.

Dyer, J.R.G., Croft, D.P., Morrell, L.J., Krause, J., 2008. Shoal composition determines foraging success in the guppy. Behav. Ecol. 20, 165-171, http://dx.doi.org/10. 1093/beheco/arn129.

Favati, A., Leimar, O., Radesäter, T., Løvlie, H., 2013. Social status and personality: stability in social state can promote consistency of behavioural responses. Proc. Biol. Sci. 281, 20132531, http://dx.doi.org/10.1098/rspb.2013.2531.

Favreau, F.-R., Goldizen, A.W., Fritz, H., Blomberg, S.P., Best, E.C., Pays, O., 2014 Within-population differences in personality and plasticity in the trade-off between vigilance and foraging in kangaroos. Anim. Behav. 92, 175-184, http://dx.doi.org/10.1016/j.anbehav.2014.04.003.

Ferrari, S., Benhaïm, D., Colchen, T., Chatain, B., Bégout, M.-L., 2014. First links between self-feeding behaviour and personality traits in European seabass Dicentrarchus labrax. Appl. Anim. Behav. Sci. 161, 131-141, http://dx.doi.org/ 10.1016/j.applanim.2014.09.019.

Harcourt, J.L., Ang, T.Z., Sweetman, G., Johnstone, R.A., Manica, A., 2009a. Social feedback and the emergence of leaders and followers. Curr. Biol. 19, 248-252, http://dx.doi.org/10.1016/j.cub.2008.12.051.

Harcourt, J.L., Sweetman, G., Johnstone, R.a., Manica, A., 2009b. Personality counts: the effect of boldness on shoal choice in three-spined sticklebacks. Anim. Behav. 77, 1501-1505, http://dx.doi.org/10.1016/j.anbehav.2009.03.004.

Harcourt, J.L., Biau, S., Johnstone, R., Manica, A., 2010a. Boldness and information use in three-Spined sticklebacks. Ethology 116, 440-447, http://dx.doi.org/10. 1111/j.1439-0310.2010.01757.x.

Harcourt, J.L., Sweetman, G., Manica, A., Johnstone, R.A., 2010b. Pairs of fish resolve conflicts over coordinated movement by taking turns. Curr. Biol. 20, 156-160, http://dx.doi.org/10.1016/j.cub.2009.11.045.

Herbert-Read, J.E., Krause, S., Morrell, L.J., Schaerf, T.M., Krause, J., Ward a, J.W. 2013. The role of individuality in collective group movement. Proc. R. Soc. B 280, 20122564, http://dx.doi.org/10.1098/rspb.2012.2564.

Hulthén, K., Chapman, B.B., Nilsson, P.A., Hollander, J., Brönmark, C., 2014. Express yourself: bold individuals induce enhanced morphological defences. Proc. R. Soc. B 281, 20132703, http://dx.doi.org/10.1098/rspb.2013.2703. 
Ioannou, C.C., Payne, M., Krause, J., 2008. Ecological consequences of the bold-shy continuum: the effect of predator boldness on prey risk. Oecologia 157 177-182, http://dx.doi.org/10.1007/s00442-008-1058-2.

Jolles, J.W., Fleetwood-Wilson, A., Nakayama, S., Stumpe, M.C., Johnstone, R.A., Manica, A., 2014. The role of previous social experience on risk-taking and leadership in three-spined sticklebacks. Behav. Ecol. 25, 1395-1401, http://dx doi.org/10.1093/beheco/aru146.

Jolles, J.W., Fleetwood-Wilson, A., Nakayama, S., Stumpe, M.C., Johnstone, R.A., Manica, A., 2015. The role of social attraction and its link with boldness in the collective movements of three-spined sticklebacks. Anim. Behav. 99, 147-153, http://dx.doi.org/10.1016/j.anbehav.2014.11.004.

Jolles, J.W., Aaron Taylor, B., Manica, A., 2016. Recent social conditions affect boldness repeatability in individual sticklebacks. Anim. Behav. 112, 139-145, http://dx.doi.org/10.1016/j.anbehav.2015.12.010.

King, A.J., Fürtbauer, I., Mamuneas, D., James, C., Manica, A., 2013. Sex-differences and temporal consistency in stickleback fish boldness. PLoS One 8, e81116, http://dx.doi.org/10.1371/journal.pone.0081116.

King, A.J., Williams, L.J., Mettke-Hofmann, C., 2015. The effects of social conformity on Gouldian finch personality. Anim. Behav. 99, 25-31, http://dx.doi.org/10. 1016/j.anbehav.2014.10.016.

Kluen, E., Brommer, J.E., 2013. Context-specific repeatability of personality traits in a wild bird: a reaction-norm perspective. Behav. Ecol. 24, 650-658, http://dx. doi.org/10.1093/beheco/ars221.

Koolhaas, J.M., Korte, S.M., Boer, S.F., De, Vegt, Van Der, B.J., Reenen, Van, C.G. 1999a. Coping styles in animals: current status in behavior and stress-physiology. Neurosci. Biobehav. Rev. 23, 925-935.

Koolhaas, J.M., Korte, S.M., De Boer, S.F., Van Der Vegt, B.J., Van Reenen, C.G., Hopster, H., De Jong, I.C., Ruis, M.A., Blokhuis, H.J., 1999b. Coping styles in animals: current status in behavior and stress-physiology. Neurosci. Biobehav. Rev. 23, 925-935.

Koolhaas, J.M., 2008. Coping style and immunity in animals: making sense of individual variation. Brain. Behav. Immun. 22, 662-667, http://dx.doi.org/10. 1016/j.bbi.2007.11.006

Kruase, J., Ruxton, G.D., 2002. Living in Groups, Oxford Series in Ecology and Evolution. Oxford University Press, New York.

Kurvers, R.H.J.M., Eijkelenkamp, B., van Oers, K., van Lith, B., van Wieren, S.E., Ydenberg, R.C., Prins, H.H.T., 2009. Personality differences explain leadership in barnacle geese. Anim. Behav. 78, 447-453, http://dx.doi.org/10.1016/j. anbehav.2009.06.002

Kurvers, R.H.J.M., van Oers, K., Nolet, B.A., Jonker, R.M., van Wieren, S.E., Prins, H.H.T., Ydenberg, R.C., 2010. Personality predicts the use of social information. Ecol. Lett. 13, 829-837, http://dx.doi.org/10.1111/j. 1461-0248.2010.01473.x.

Kurvers, R.H.J.M., Adamczyk, V.M., a, P., van Wieren, S.E., Prins, H.H.T., 2011. The effect of boldness on decision-making in barnacle geese is group-size-dependent. Proc. Biol. Sci. 278, 2018-2024, http://dx.doi.org/10. 1098/rspb.2010.2266.

Laland, K., Williams, K., 1997. Shoaling generates social learning of foraging information in guppies. Anim. Behav. 53, 1161-1169.

Laskowski, K.L., Bell, A.M., 2013. Competition avoidance drives individual differences in response to a changing food resource in sticklebacks. Ecol. Lett. 16, 746-753, http://dx.doi.org/10.1111/ele.12105.

Laskowski, K.L., Bell, A.M., 2014. Strong personalities, not social niches, drive individual differences in social behaviours in sticklebacks. Anim. Behav. 90, 287-295, http://dx.doi.org/10.1016/j.anbehav.2014.02.010.

Laskowski, K.L., Pruitt, J.N., 2013. Evidence of social niche construction: persistent and repeated social interactions generate stronger personalities in a social spider. Proc. Biol. Sci. 281, 20133166, http://dx.doi.org/10.1098/rspb.2013. 3166.

Leblond, C., Reebs, S., 2006. Individual leadership and boldness in shoals of golden shiners (Notemigonus crysoleucas). Behaviour 143, 1263-1280.

Magnhagen, C., Bunnefeld, N., 2009. Express your personality or go along with the group: what determines the behaviour of shoaling perch? Proc. Biol. Sci. 276 3369-3375, http://dx.doi.org/10.1098/rspb.2009.0851.

Magnhagen, C., Staffan, F., 2003. Social learning in young-of-the-year perch encountering a novel food type. J. Fish Biol. 63, 824-829, http://dx.doi.org/10 1046/j.1095-8649.2003.00189.x.

Magnhagen, C., Staffan, F., 2005. Is boldness affected by group composition in young-of-the-year perch (Perca fluviatilis)? Behav. Ecol. Sociobiol. 57, 295-303, http://dx.doi.org/10.1007/s00265-004-0834-1.

Magnhagen, C., 2007. Social influence on the correlation between behaviours in young-of-the-year perch. Behav. Ecol. Sociobiol. 61, 525-531, http://dx.doi org/10.1007/s00265-006-0280-3.

Maximino, C., de Brito, T.M., da Silva Batista, A.W., Herculano, A.M., Morato, S., Gouveia, A., 2010a. Measuring anxiety in zebrafish: a critical review. Behav. Brain Res. 214, 157-171, http://dx.doi.org/10.1016/j.bbr.2010.05.031.

Maximino, C., Marques de Brito, T., Dias, C.A.G., de, M., Gouveia, A., Morato, S., 2010b. Scototaxis as anxiety-like behavior in fish. Nat. Protoc. 5, 209-216 http://dx.doi.org/10.1038/nprot.2009.225.

McElreath, R., Luttbeg, B., Fogarty, S.P., Brodin, T., Sih, A., 2007. Evolution of animal personalities. Nature 450, E5, http://dx.doi.org/10.1038/nature06326, discussion E5-6.

Moretz, J.A., Martins, E.P., Robison, B.D., 2007. Behavioral syndromes and the evolution of correlated behavior in zebrafish. Behav. Ecol. 18, 556-562, http:// dx.doi.org/10.1093/beheco/arm011.
Nakayama, S., Harcourt, J.L., Johnstone, R.a., Manica, A., 2012. Initiative, personality and leadership in pairs of foraging fish. PLoS One 7, e36606, http://dx.doi.org/ 10.1371/journal.pone.0036606.

Nomakuchi, S., Park, P.J., Bell, M.a., 2009. Correlation between exploration activity and use of social information in three-spined sticklebacks. Behav. Ecol. 20, 340-345, http://dx.doi.org/10.1093/beheco/arp001.

Nussey, D.H., Wilson, A.J., Brommer, J.E., 2007. The evolutionary ecology of individual phenotypic plasticity in wild populations. J. Evol. Biol. 20, 831-844, http://dx.doi.org/10.1111/j.1420-9101.2007.01300.x.

Ord, T.J., Stamps, J.A., Losos, J.B., 2010. Adaptation and plasticity of animal communication in fluctuating environments. Evolution 64, 3134-3148, http:/ dx.doi.org/10.1111/j.1558-5646.2010.01056.x.

Øverli, Ø., Sørensen, C., Pulman, K.G.T., Pottinger, T.G., Korzan, W., Summers, C.H., Nilsson, G.E., 2007. Evolutionary background for stress-coping styles: relationships between physiological, behavioral, and cognitive traits in non-mammalian vertebrates. Neurosci. Biobehav. Rev. 31, 396-412, http://dx. doi.org/10.1016/j.neubiorev.2006.10.006.

Pike, T.W., Laland, K.N., 2010. Conformist learning in nine-spined sticklebacks' foraging decisions. Biol. Lett. 6, 466-468, http://dx.doi.org/10.1098/rsbl.2009. 1014.

Pruitt, J.N., Reichert, S.E., 2011. How within-group behavioural variation and task efficiency enhance fitness in a social group. Proc. Roy. Soc. B 278, 1209-1215, http://dx.doi.org/10.1098/rspb.2010.1700.

Quinn, J.L., Cole, E.F., Bates, J., Payne, R.W., Cresswell, W., 2012. Personality predicts individual responsiveness to the risks of starvation and predation. Proc. Biol. Sci. 279, 1919-1926, http://dx.doi.org/10.1098/rspb.2011.2227.

Rosenthal, S.B., Twomey, C.R., Wu, H.S., Couzin, I.D., 2015. Revealing the hidden networks of interaction in animal groups allows prediction of complex behavioral contagion. Proc. Natl. Acad. Sci. 112, 4690-4695.

Ruiz-Gomez, M., de, L., Kittilsen, S., Höglund, E., Huntingford, F.A., Sørensen, C., Pottinger, T.G., Bakken, M., Winberg, S., Korzan, W.J., Øverli, Ø., 2008. Behavioral plasticity in rainbow trout (Oncorhynchus mykiss) with divergent coping styles: when doves become hawks. Horm. Behav. 54, 534-538, http:// dx.doi.org/10.1016/j.yhbeh.2008.05.005.

Schuett, W., Dall, S.R.X., 2009. Sex differences, social context and personality in zebra finches, Taeniopygia guttata. Anim. Behav. 77, 1041-1050, http://dx.doi. org/10.1016/j.anbehav.2008.12.024.

Serra, E.L., Medalha, C.C., Mattioli, R., 1999. Natural preference of zebrafish (Danio rerio) for a dark environment. Braz. J. Med. Biol. Res. 32, 1551-1553.

Sih, a, Bell, a M., 2008. Insights for behavioral ecology from behavioral syndromes. Adv. Study Behav. 38, 227-281, http://dx.doi.org/10.1016/S00653454(08)00005-3.

Sih, A., Del Giudice, M., 2012. Linking behavioural syndromes and cognition: a behavioural ecology perspective. Philos. Trans. R. Soc. Lond. B: Biol. Sci. 367, 2762-2772, http://dx.doi.org/10.1098/rstb.2012.0216.

Sih, A., Bell, A., Johnson, J.C., 2004a. Behavioral syndromes: an ecological and evolutionary overview. Trends Ecol. Evol. 19, 372-378, http://dx.doi.org/10. 1016/j.tree.2004.04.009.

Sih, A., Bell, A., Johnson, J.C., 2004b. Behavioral syndromes: an ecological and evolutionary overview. Trends Ecol. Evol. 19, 372-378, http://dx.doi.org/10. 1016/j.tree.2004.04.009.

Sih, A., Cote, J., Evans, M., Fogarty, S., Pruitt, J., 2012. Ecological implications of behavioural syndromes. Ecol. Lett. 15, 278-289, http://dx.doi.org/10.1111/j. 1461-0248.2011.01731.x.

Sneddon, L.U., 2003. The bold and the shy: individual differences in rainbow trout J. Fish Biol. 62, 971-975, http://dx.doi.org/10.1046/j.1095-8649.2003.00084.x.

Stamps, J., Groothuis, T.G.G., 2010. The development of animal personality: relevance, concepts and perspectives. Biol. Rev. Camb. Philos. Soc. 85, 301-325, http://dx.doi.org/10.1111/j.1469-185X.;1;2009.00103.x.

Stephenson, J.F., Whitlock, K.E., Partridge, J.C., 2011. Zebrafish preference for light or dark is dependent on ambient light levels and olfactory stimulation. Zebrafish 8, 17-22, http://dx.doi.org/10.1089/zeb.2010.0671.

Sumpter, D.J.T., 2006. The principles of collective animal behaviour. Philos. Trans. R. Soc. Lond. B: Biol. Sci. 361, 5-22, http://dx.doi.org/10.1098/rstb.2005.1733.

Tanner, C.J., Jackson, A.L., 2012. Social structure emerges via the interaction between local ecology and individual behaviour. J. Anim. Ecol. 81, 260-267, http://dx.doi.org/10.1111/j.1365-2656.2011.01879.x.

Teyssier, A., Bestion, E., Richard, M., Cote, J., 2014. Partners' personality types and mate preferences: predation risk matters. Behav. Ecol. 25, 723-733, http://dx doi.org/10.1093/beheco/aru049.

Toms, C.N., Echevarria, D.J., 2014. Back to basics: searching for a comprehensive framework for exploring individual differences in zebrafish (Danio rerio) behavior. Zebrafish 11, 325-340, http://dx.doi.org/10.1089/zeb.2013.0952.

Toms, C.N., Echevarria, D.J., Jouandot, D.J., Mississippi, S., 2010. A methodological review of personality related studies in fish: focus on the shy-bold axis of behavior. Int. J. Comp. Psychol. 23, 1-25.

van Oers, K., Klunder, M., Drent, P.J., 2005. Context dependence of personalities: risk-taking behavior in a social and a nonsocial situation. Behav. Ecol. 16, 716-723, http://dx.doi.org/10.1093/beheco/ari045.

Ward, A.J.W., Thomas, P., Hart, P.J.B., Krause, J., 2004 Correlates of boldness in three-spined sticklebacks (Gasterosteus aculeatus). Behav. Ecol. Sociobiol. 55 561-568, http://dx.doi.org/10.1007/s00265-003-0751-8.

Watters, J., Sih, A., 2005. The mix matters: behavioural types and group dynamics in water striders. Behaviour 142, 1417-1431, http://dx.doi.org/10.1163/ 156853905774539454 
Webster, M.M., Laland, K.N., 2009. Evaluation of a non-invasive tagging system for laboratory studies using three-spined sticklebacks Gasterosteus aculeatus. Fish Biol. 75, 1868-1873, http://dx.doi.org/10.1111/j.1095-8649.2009.02374.x.

Webster, M.M., Ward, A.J.W., 2011. Personality and social context. Biol. Rev. Camb. Philos. Soc. 86, 759-773, http://dx.doi.org/10.1111/j.1469-185X.;1;2010. 00169.x.

Webster, M.M., Ward, A.J.W., Hart, P.J.B., 2007. Boldness is influenced by social context in threespine sticklebacks (Gasterosteus aculeatus). Behaviour 144 , 351-371, http://dx.doi.org/10.1163/156853907780425721.

Wolf, M., Krause, J., 2014. Why personality differences matter for social functioning and social structure. Trends Ecol. Evol. 29, 306-308, http://dx.doi. org/10.1016/j.tree.2014.03.008
Wolf, M., Weissing, F.J., 2010. An explanatory framework for adaptive personality differences. Philos. Trans. R. Soc. Lond. B: Biol. Sci. 365, 3959-3968, http://dx. doi.org/10.1098/rstb.2010.0215.

Wolf, M., van Doorn, G.S., Leimar, O., Weissing, FJ., 2007. Life-history trade-offs favour the evolution of animal personalities. Nature 447, 581-584, http://dx. doi.org/10.1038/nature05835.

Wolf, M., van Doorn, G.S., Weissing, F.J., 2008. Evolutionary emergence of responsive and unresponsive personalities. Proc. Natl. Acad. Sci. U. S. A. 105 15825-15830, http://dx.doi.org/10.1073/pnas.0805473105. 